\title{
Study on Out of Africa from the Perspective of Heterotopia
}

\author{
Yan Wang and Xiaolan Lei
}

\begin{abstract}
Out of Africa gives us different imaginations of spaces from the literal meaning, and many scholars have analyzed it from different perspectives. However, never has Foucault's theory of heterotopia. This paper tries to give an analysis about the thinking spaces in this article combined with the six features of Foucault's heterotopia, then shows us a different Africa and different ways of thinking.
\end{abstract}

Index Terms - Out of Africa, foucault, heterotopias.

\section{INTRODUCTION}

Victor-Hugo once said, "Africa is the most mysterious place in areas that people do not know [1]." In literature field, this magic field also attracted many writers, and the famous Danish woman writer Isak Dinesen was one of them.

Karen Blixen, 1885-1962, formerly called Isak Dinesen, who was born on April 17, 1885 in Danish Island, a noble family in Longseltz .The young Karen has showed her gift in writing and painting, and when she was 22 , she published her first novella. In 1912, Karen was engaged with her cousin, baron Blover Von Brikson-Finnick and came to Africa to start a coffee plantation in Kenyain which she stayed for 17 years. After the bankruptcy, Blixen returned to Danmark, and started her writing career. In 1934, she published her first short stories collection seven Gothic tales, and became famous overnignt. After that, she published Winter's Tales in 1942, last tales in 1957, Anecdotes of Destiny in 1958 and Shadows on the Grass in 1960, etc. a series of short stories. Among them, Blixen is best known for Out of Africa, an account of her life while living in Kenya. In 1937, the publication of Isak Dinesen's autobiographical novel, which has been published under this pseudonym, has aroused widespread concern in European and American literary circles. The pseudonym of Karen comes from the "Bible", and the Old Testament accounts: Sarah got the revelation of God and gave her a son. But she was too old to have a son, then Sarah laughed, named her son Isak later. Isak means the man who laughs in Hebrew, and Karen-Blixen also wants to be distinguished by using this unique, humorous name [2].

Manuscript received April 28, 2017; revised July 23, 2017

Yan Wang is with Northwestern Polytechnical University, China (e-mail: violetvcc@163.com).

Xiaolan Lei is with Northwestern Polytechnical University, China (e-mail: xiaolanlei@nwpu.edu.cn).

\section{RESEARCH STATUS}

Karen Blixen has high visibility in European literary circles. The British critic John Davenport spoke highly of her," In our time, few writers like her write less but refined [3]". The Atlantic Monthly commended Karen "One of the most elegant and unique artists of our time [3]." "The New York Times" commented that Karen was "a writer with extraordinary imagination, smart and intelligent [3]." The literary critic, Jacques Henriksen, said that Karen is "the messenger of the distant journey, to tell people that there is hope in the world [3]."For out of Africa, the British "Guardian" commented on it "depicts a passionate story, with the idyllic language to recall the lost homeland [3]". Karen and Andersen are known as the Danish "literary treasures" and she is the winners of the Andersen Award (1955) and the Pinto Pidan Award (1959).In 1954 and 1957, Karen has been included in the candidates list of the Noble prize in literature. In 1954, the great writer Hemingway stated that Blixen deserved the prize more than he did and said that if the author of "Out of Africa," the beautiful Karen Blixen, won the Nobel Prize in Literature, I will be more happy today when he won the prize. In 1957, she was elected honorary academician of the American Academy of Sciences and in 1960, she was elected to the academician of Danish Acadamy. Since 1960s, researches on Blixen in Europe and the United States made great progress and in her hometown, nobody does not know her. Copenhagen established the Karen Brixen Association, and founded the journal Brixson study in 1975.This European white lady who wrote about African life can be described as a splendor in the world literature platform. However, such a legendary writer in mainland China has not got enough attention of the literary criticism. At present, the domestic research on Karen Blixen is still feeble. This research will analyse the article translated by Zhou Guoyong \& Zhang He, and published by East China Normal University Press.

\section{RESEARCH SIGNIFICANCE}

Through the data collection in China national knowledge internet and other academic websites, the researches on out of Africa are more from the following perspectives: the colonial and postcolonialist studies; the ecological study; the Feminist Criticism study; the narrative study; and the last one is the summary of different studies on it. Other papers also analyse the out of Africa from the cross-cultural writing, symbolic meaning, metaphorical perspective, psychology and other different angles. Though there are many different research angles on out of Africa, few research is from the perspective of heterogeneous space to Kenya, this beautiful 
African grassland. This paper tries to discover a different Africa from a brand new view to give the readers a new way of thinking.

\section{FOUCAULT'S HETEROTOPIA THEORY}

Foucault puts forward the concept of heterotopia in his speech draft Heterotopia in 1967. He illustrates the six characteristics of this space. Firstly, there is no single culture in the world that does not have a heterogeneous space, but the forms of heterotopia are varied. There are two spaces in the past, one is "some privileged or sacred or taboo places" in primitive society which belong to "crisis heterotopia." The other one is more modern, "heterotopias of deviation," like rest homes, hospitals and prisons. They exist in the familiar daily spaces, but in terms of the doctrine of the mean or the norm, the act is deviant [4]. Secondly, in contrast to a culture, another culture that is different from its own is a heterogeneous space [4]. In the same nation, different times, different social forms will create their own unique spaces. Therefore, "in the same nation or different nations, different times in which each of the relatively constant society is a 'Heterotopia"'. At the same time, every heterotopia has "a precise and special operation." It changes its mode of operation with the changes of history and culture. For example, from the past that people's worship of death to the personalization of modern death, the status of tomb, the heterotopia, has changed which was once the symbol of "the existence of a complete hierarchical system" has become the dark "another city" now. Thirdly, heterotopia can be a single real place that juxtaposes several places that can't be compared [4]. Foucault takes theaters, cinemas and gardens as examples which indicated that the formation of heterotopias may be real and may be imagined. "Can not be compared" means it seems there is no direct relation between different spaces but for a specific function or purpose, they are reasonably connected as a whole. Fourthly, heterotopia "is often associated with the fracture of time" [4]. The tomb mentioned above is a typical heterotopia at which the boundaries between life and death are distinct and exists some sort of association; here, time is hung up forever. Museums and libraries are heterotopia which accumulated time. And modern people can step into it and get access to the life, culture and thought of each age. Fifthly, 'Heterotopias of ritual or purification' are spaces that are isolated and penetrable yet not freely accessible like a public place [4]. To get in one must have permission and make certain gestures such as in a sauna or a hammam. Sixthly, Heterotopia has a function in relation to all of the remaining spaces [4]. The two functions are: heterotopia of illusion creates a space of illusion that exposes every real space, and the heterotopia of compensation is to create a real space-a space that is other. The former is like a brothel, the latter such as some colonies. In addition, boat is a floating, flowing space which can link up a variety of spaces including brothel and colonies. And Foucault regards it as an "outstanding heterotopia" [2].

More detailed description of Foucault's heterotopia can help the understanding of different spaces in Karen's out of Africa. It uses the special spaces to show the author' 17 years with the pain and disillusion and may be more of which is her grateful experience. The paper will analyze the obvious heterotopias in the works combined with Foucault's heterotopia theory.

Firstly, there exists no single culture without heterotopia, so does the African culture. Out of Africa is all about the unknown Africa which is distilled up through from six thousand feet, like the strong and refined essence. Whether the African plantation located in the foot of Ngong hills, or the boundless plain of Marseille protected area in which once you get immersed in it, the happy heart will be excited to call up, or look forward to the fascinating African primitive grassland and ranch, they are real presence [5]. The heterotopias here refer to the "crisis heterotopia" in primitive society. They are in contrast with the furniture building, artificial park which is another space that is isolated from modern society." In the daytime, you felt that you had got high up, near the sun, but the early mornings and evenings were limpid and restful and the nights were cold" [5]. Up in this high air you breathed easily, drawing in a vital assurance and lightness of heart. In the highlands you woke up in the morning and thought: Here I am, where I ought to be [5]." All the time the feeling of immense freedom is surrounding him and running through him like air and light, an unearthly bliss. He is a privileged person, the one who has got nothing to do, but for whose enrichment and pleasure all things are brought together; the Kings of Tarshish shall bring gifts [5]". From there, to the South-West, I saw the Ngong Hills. The noble wave of the mountain rose above the surrounding flat land, all air-blue. But it was so far away that the four peaks looked trifling, hardly distinguishable, and different from the way they looked from the farm. The outline of the mountain was slowly smoothed and leveled out by the hand of distance. The chief feature of the landscape, and of your life in it, was the air. Looking back on a sojourn in the African highlands, you are struck by your feeling of having lived for a time up in the air. They have shown us neither fat on it and no luxuriance anywhere but unparalleled Africa.

Secondly, due to the differences between national culture and historical development, Karen's African society is a heterotopia in the eyes of Chinese readers. It is a 'Wonderland' with Eden color falling from heaven full of conflicting social and economic forces, ideological contradictions, elusive, often violent vitality. Africa this space is full of a variety of small heterotopias: There is a religious conflict latent everywhere in daily life. In the post-colonial era of Africa, the greatest legacy of the colonists is religion the spread of religion in African colonial states is another form of colonialism, and his occupation and domination of colonies is different from guns and is also different from language. It affects people's spiritual world directly, and fundamentally changes people's values of life. The core of African traditional religion is the worship to nature and ancestors, and the so-called Gods is nature, ancestors is the ancestors. It is clear that many aborigines have confused the Supreme God of their faith and the God of Christianity, and have transferred their faith in nature and supreme gods to Christian God in traditional religion. Aborigines' respect for the chiefs and the promise of chiefs on everything reveal the African primitive tribe of 
the patrilineal society. They have no fear of anything, love for danger, and the creative answers to the declaration of their destiny - the earth's response to the voice of heaven, which is the real courage of the indigenous people. They are creatures filled with wild characteristics. They seclude from the world, and live with a firm, persistent courage from the outside world. But they embrace the feelings of gratitude for foreigners who respect for the gods of all creations and they seem to have insight into everything, some kind of natural divine power. When the author finishes all the stuffs and is about to walk out of Africa, the old native men who are chilly people, and generally wrap and muffle themselves up well in furs and blankets, but here they were naked, as if solemnly stating the formidable truth and resolved to hold a Ngoma for the author. These Ngomas of the Ancients had been great functions in the past, but now they were rarely danced. Also these native men use their own way to mourn Danys who is dead due to the flight crash. The determination of living together of the indigenous people is surprising the author. They are united and maintain their nature. If they are to leave their land, there must be people around them who know their homeland in order to verify their dignity and try to keep their traditions. All of these heterotopias show the mystery and uniqueness of the amazing Africa.

Thirdly, the heterotopia can be a single real place that juxtaposes several irrelevant places, as a function superimposed space. Located at the foot of the Ngong Hills, Karen's African farm, is not only the place where the African people are working but the place where the colonists can rest or stay for a short time. African indigenous people are slaved in their own home. Africa, with its long history and splendid culture, begins to be cruelly trampled by the capitalist countries at the beginning of the 15th century. By the beginning of the twentieth century, the vast majority of Africa has become a Western colony. Africa, as the home of the indigenous people, is also a colony invaded and plundered by the western colonists. The plains lay below Denys's cemetery, to the South, far away, below the changing clouds, lay the broken, dark blue foot-hills of Kilimanjaro. A strange thing that had happened by Denys' grave, Alion and a lioness have come there, and stood, or lain, on the grave for a long time. The cemetery here is an open space, in fact, it has a specific function of multi-spaces superposition. Firstly, it exists as an inch of Africa earth. Secondly, though it is a place for the die Denys who is a colonist but for the native men his death was a bereavement. And finally it is a habitat for the lion. Although the cemetery cuts the life off from death, blends Denys and nature. And so the boundaries of life and death is not so clear, making the short-term death into eternity. In addition, the cemetery is the only space that can integrate time, space and all. Finally, the appearance of the lion to cemetery brings another space effect, lion as a distinguished symbol, representing the distinguished character of Denys. But here it is more than this, the lion, symbolizing the African plain, the magic nature, who frequently appears by Denys's cemetery, in fact, represents a blending state. Perhaps, Denys, the colonist, at that moment real enters into the African natural space from other space.

Fourthly, heterotopia "is often associated with the fracture of time." The cemetery mentioned above is a typical heterotopia. Here, the boundaries of life and death are distinct and there is some sort of association; here, time is forever suspended. Although Denys is cut off into another world, the cemetery seemed to have rested the time when Denys was here, and the feelings of African indigenous people for Denys are also frozen by the native people's enthusiasm. Denys is also at that moment integrated with the African grassland, and no longer exist as a foreigner. "The Natives had known Denys better than the white people; to them his death was a bereavement." The presence of the cemetery and the lions thus keep Denys retaining forever in Africa and never leave.

Fifthly, heterotopia's inclusive and exclusion mainly manifest in: though African plain is as a colony, it has a magical magic and summoning force, like a never disturbed space. In such a culture, people can not help worrying about their own cultural identity, whether they should blend with each other or oppose to each other? "I", Berkeley and Denys respond to the former instinctly. British royal pioneers Berkeley Cole and Denys Finch-Hatton move to Africa, but the British friends feel pity for them. However, in the colony, they are highly respected and adored, "they bore their exile with a good grace [5]." Berkeley had lost his temper and had hit the Somali, and at the very same moment he had one straight back in my face, which indicated that these two are almost equal. "When Berkeley died, the country changed. Some standards were lowered: a standard of wit... a standard of gallantry...a standard of humanity [5]." Berkeley became the incarnation of wisdom, gallocence and humanity in the eyes of the indigenous people. Denys died in the plane crash, "The Natives had known Denys better than the white people; to them his death was a bereavement [5]". And for many years after this day the Colony felt Denys's death as a loss which could not be recovered. "He had taken in the country, and in his eyes and his mind it had been changed, marked by his own individuality, and made part of him. Now Africa received him, and would change him, and make him one with herself [5]." "I" with 17 years of painstaking results bankruptcy, no money to run, had to sell it. Taking into account the tenant's livelihood problems, "I" talked with the local British government several times, fighting land for them, and then left Africa. It is clear that the author put the black and white, "I" and the British aristocracy on the same level of inspection, they have the equal opportunities for dialogue. Here, the indigenous and white, the Danish "I" and the British nobles are communicating with each other, both cultures are also engaged in mutual accommodation. In this post-colonial or non-colonial or even anti-colonial context, we finally can hear the weak voice of the "others." That is more worthy of our thought: when the weak discourse clashed with strong discourse, it must be weak or not? When the central culture clashed with and the edge culture, it must be the latter die? Out of Africa, this book not only provides us with a broad mind but also implies the best answer.

Sixthly, cars and planes, as heterotopias that appeared in Karen's novels, are not only a typical symbol of advanced culture of Africa, but they also like ships, with their mobility to connect the various spaces and places. Cars, planes and boats, are relatively closed spaces. In the article Karen drove the people to sent wartime supplies, and later only a few 
colonists had the power to drive the car. The car connects the plain with fresh air and spreads herbs fragrant and the chaos of the First world war which highlights the unique quiet and no disturbing "heterotopia" of the early 20th century. Similarly, the airplane, as a symbol of colonial status, is brought into the African plain who connects the economically developed colonies and the relatively backward but quiet Africa and traces that aircraft left in the African plain together to show the vastness and tranquility of Africa plain in the 1930s.

\section{CONCLUSION}

As some scholars have said: "The presence of heterotopia, is one of the postmodern variants of utopia [4]." In the ecological literature with utopian character, writers often set up utopian heterotopias, with the original, wild "other" space to be away from the system of the civilized society, the traditional constraints to show the vast and deep features. With the weak or stagnant or bustling modern space to form a strong contrast to the formation of the space of the rebellion and resistance. Out of Africa is the author's true feelings of the real Africa, as an indigenous landscape space being away from the modern civilization, remembers the Poet's words:

\section{Noble found I \\ ever the Native, and insipid the Immigrant [5]}

Using heterotopias theory to read out of Africa is not to let us go too original, wild, but to think. When the convenient life we pursued created by the modern technology surpasses the original simple pace, people want to 'flee to' another space which is constructed by green grass, blue sky. Especially when the smog replaces the fresh air, greys the green, we have to re-examine, compared to the African plain, whether the modern world created by human has become fetters to our way to a pure heterotopia world.

\section{ACKNOWLEDGEMENT}

Here I want to say thanks to one of my teachers, Ms. Zang, who teaches literature of western. And here comes the paper about the Heterotopia. Secondly, to my supervisor, who gives me the chance to get access to the course of literature. More importantly, they all give me lots of invaluable advices on how to choose the topic and how to write during the course. Also, thanks to the classmates, they give me a new way of thinking.

\section{REFERENCES}

[1] X. M. Wan, "On out of Africa: A post-colonial and feminist reading," Journal of Sichuan International Studies University, 2003, no. 9, pp. 80-82.

[2] laddin. [Online]. Available https://baike.baidu.com/item/\%E5\%87\%AF\%E4\%BC\%A6\%C2\%B7\% E5\%B8\%83\%E9\%87\%8C\%E5\%85\%8B\%E6\%A3\%AE/8900298?fr=a laddin

[3] Yi Wang, "Who am I," Jilin University, 2015.

[4] Y. H. Liu, "Reading heterotopia in Oates's fictions from Foucault's heterotopia theory," Journal of Guangxi Normal University: Philosophy and Social Sciences Edition, 2011, no. 10, pp. 53-56.

[5] K. Blixen, Out of Africa, Trans. Guoyong Zhou\& He Zhang, East China Normal University Press, 2013.

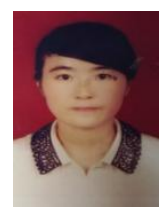

Yan Wang comes from Shaanxi, China and was born on 19 Oct 1987.Doing master's degree on applied linguistics at the School of Foreign Languages in Northwestern Polytechnical University, and will earn the graduate's diploma in March, 2018.

She gets the scholarship twice during doing the master's degree, and she is the vice president of the association of the graduate and has obtained a third prize of academic annual conference and has attended the international conference held in Singapore at June $5^{\text {th }}$.Current research interests mainly focus on the economics of language and the western literature.

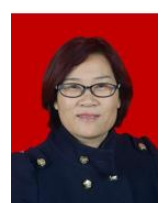

Xiaolan Lei comes from Shaanxi, China and teaches at the School of Foreign Languages in Northwestern Polytechnical University. Mainly studys on the economics of language and the applied linguistics.

She has published more than three papers. An Analysis on the Economic Value of Languages [J]. Journal of Xi'an Jiaotong University (Social Sciences), 2009, 29(6): 107-110.etc.And participated in many research projects as the first participant. 